\title{
Localisation of vitronectin receptor immunoreactivity and tartrate resistant acid phosphatase activity in synovium from patients with inflammatory or degenerative arthritis
}

\author{
B A Ashton, I K Ashton, M J Marshall, R C Butler
}

\begin{abstract}
The influx of cells into the synovial intima in rheumatoid joints may include osteoclasts and their precursors. The distribution of osteoclast markers-namely, tartrate resistant acid phosphatase activity and the expression of vitronectin receptor (shown with monoclonal antibodies $13 \mathrm{C2}$ and 23C6)-was therefore examined in synovium obtained from patients with rheumatoid (RA) or degenerative (OA) arthritis. Tartrate resistant acid phosphatase positive cells were found in frozen sections of $60 \%(n=30)$ of $R A$ and $69 \%(n=29)$ of OA synovial membranes. Whereas all synovia tested (four RA, four OA) showed diffuse staining of the lining cells with $13 \mathrm{C} 2,55 \%(n=$ 11) of RA and $57 \%(n=14)$ of OA synovial membranes contained isolated cells stained with $23 \mathrm{C} 6$ scattered throughout the tissue. In cultures of synovial cells, tartrate resistant acid phosphatase positive, multinuclear, and 23C6 positive cells were found; these cells did not, however, form resorption pits on bone slices. The results show that fully differentiated osteoclasts are uncommon in synovium from patients with either degenerative or inflammatory arthropathies.
\end{abstract}

(Ann Rheum Dis 1993; 52: 133-137)

In joints affected by rheumatoid arthritis (RA) there is a substantial increase in the numbers of two types of cell believed to be of the monocyte/ macrophage series-that is, the type A synoviocyte and the osteoclast.

The pronounced hyperplasia of the cells of the synovial lining in patients with RA is believed to be a consequence of the influx of type A synoviocytes derived from marrow, ${ }^{12}$ which display features of the monocyte/macrophage lineage. ${ }^{3}$

Osteoclasts are the cells predominantly, possibly exclusively, responsible for bone resorption and they have been found at the erosive pannus/bone interface in rheumatoid joints. ${ }^{4}$ There is good evidence that osteoclasts are derived from a bone marrow haemopoietic stem cell $^{5}$ by fusion of blood borne mononuclear cells. $^{6}$ The signalling mechanism responsible for osteoclast recruitment in a particular location is not understood. It is not known if these cells arrive and develop independently or whether, in areas where the pannus or synovial lining comes in contact with bone, synoviocytes can differentiate to osteoclasts and bring about bone erosion.

In our present study evidence for the presence of osteoclasts or their precursors within synovium has been sought by morphological and in vitro tissue culture studies. The distribution of markers used to define osteoclasts has been assessed in synovium from patients with RA or OA. The markers used were the monoclonal antibodies $13 \mathrm{C} 2$, which reacts with an epitope on the $\alpha v$ integrin and 23C6, which reacts with the $\alpha v \beta 3$ heterodimer of the vitronectin receptor, ${ }^{7}$ and tartrate resistant acid phosphatase found at high concentration in osteoclast lysosomes. ${ }^{8}$

The potential of dispersed synovial cells to differentiate in vitro into osteoclasts was studied with the same cytochemical markers and resorptive function was assessed with a pit forming assay.

\section{Methods}

TISSUE PREPARATION

Synovium was obtained from patients with either RA $(n=30)$ or OA $(n=29)$ who were undergoing surgery, usually for joint replacement. Patients with RA satisfied the criteria for classical or definite disease, ${ }^{9}$ and OA was diagnosed on the basis of typical radiographic findings. The synovium was immediately frozen in liquid nitrogen at $-180^{\circ} \mathrm{C}$ and $7 \mu \mathrm{m}$ sections were cut on a cryostat. The sections were fixed in acetone for 10 minutes and stored at $-60^{\circ} \mathrm{C}$. Frozen sections of osteoclastoma were prepared as positive controls and muscle, liver, kidney, and synovial capsule were prepared for use as negative controls. Also, imprints of bone from one day old rabbits were prepared as previously described. ${ }^{10}$

\section{IMMUNOCHEMISTRY}

Monoclonal antibodies $13 \mathrm{C} 2$ and $23 \mathrm{C} 6$ were obtained from Dr M Horton, Imperial Cancer Research Fund, London, as a culture supernatant and used undiluted. ${ }^{10}$ Tissue sections were thawed, rehydrated with phosphate buffered saline (PBS) containing 10\% human serum for 20 minutes, and incubated for 30 minutes with antisera or with PBS and $10 \%$ human serum in a humid chamber at room temperature. The glass slides were washed $(3 \times 5$ minutes) with PBS and then incubated for 60 minutes with a gold linked secondary antibody (Janssen Auroprobe LM) diluted 1:40 in PBS containing $0 \cdot 1 \%$ bovine serum albumin. The sections were washed ( $3 \times 5$ minutes) with PBS then incubated for 15 minutes at room temperature in silver reagent (Janssen, Intense $M$ ). The slides were washed with deionised water and the silver 
enhancement procedure was repeated if necessary. Sections were then lightly stained with haematoxylin and eosin. Consecutive sections were fixed with citrate acetone and stained for tartrate resistant acid phosphatase (Sigma leucocyte acid phosphatase kit) or with haematoxylin and eosin.

\section{CELL PREPARATION}

Synovium was diced with scissors and shaken overnight in $20 \mathrm{ml} \alpha$ minimal essential medium ( $\alpha$ MEM; Gibco). The tissue was further disrupted in a pipette and the cells were harvested by centrifugation at $100 \mathrm{~g}$. Cells were resuspended in $\alpha$ MEM containing $20 \%$ horse serum (Flow Laboratories), $1 \times 10^{-8}$ M 1,25dihydroxy vitamin $\mathrm{D}_{3}$ (Roche) and $2 \times 10^{-10} \mathrm{M}$ recombinant human interleukin $1 \alpha$ (Hoffman LaRoche), and plated at $1 \times 10^{6}$ cells $/ \mathrm{ml}$ in the same medium. Cultures were maintained for up to four weeks in $5 \% \mathrm{CO}_{2}$ at $37^{\circ} \mathrm{C}$ with weekly medium changes. At intervals from one to four weeks cultures were fixed with methanol. Individual wells were stained for tartrate resistant acid phosphatase (TRAP assay kit, Sigma) or rehydrated with PBS containing $10 \%$ human serum and stained with the monoclonal antibodies as already described.

\section{RESORPTION ASSAY}

Longitudinal sections (approximately $0.75 \times$ $5 \times 5 \mathrm{~mm}$ ) of bovine cortical bone that had been cut on a Buehler low speed saw were sterilised by exposure to ultraviolet light and placed in individual wells containing human synovial cells that had been cultured for three weeks. Bone slices were removed at intervals up to eight days and fixed in $8 \%$ glutaraldehyde in $0.4 \mathrm{M}$ sodium cacodylate buffer $(\mathrm{pH} \mathrm{7.3)}$ for 10 minutes. The bone slices were then stained with $1 \%$ toluidine blue in $0.5 \%$ borax buffer, rinsed in alcohol, air dried, and examined under reflected light and by scanning electron microscopy for resorption cavities.

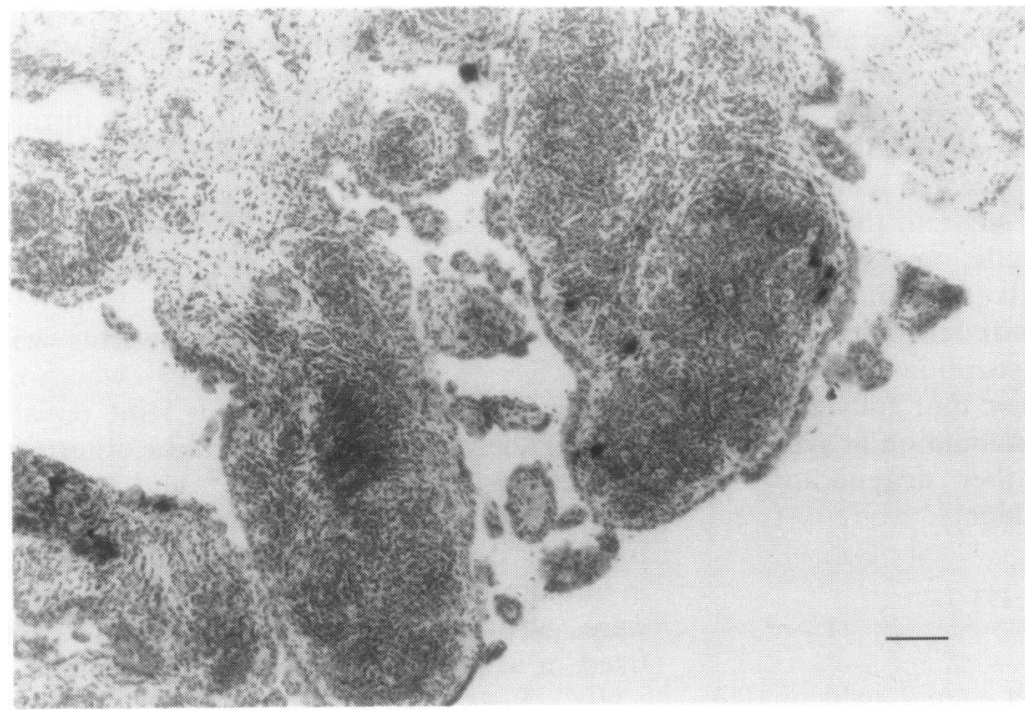

Figure 1 Section of synovium from a patient with $R A$ showing tartrate resistant acid phosphatase activity in cells in subintimal layer of synovium. Section counterstained with haematoxylin and eosin. Bar $=100 \mu \mathrm{m}$.

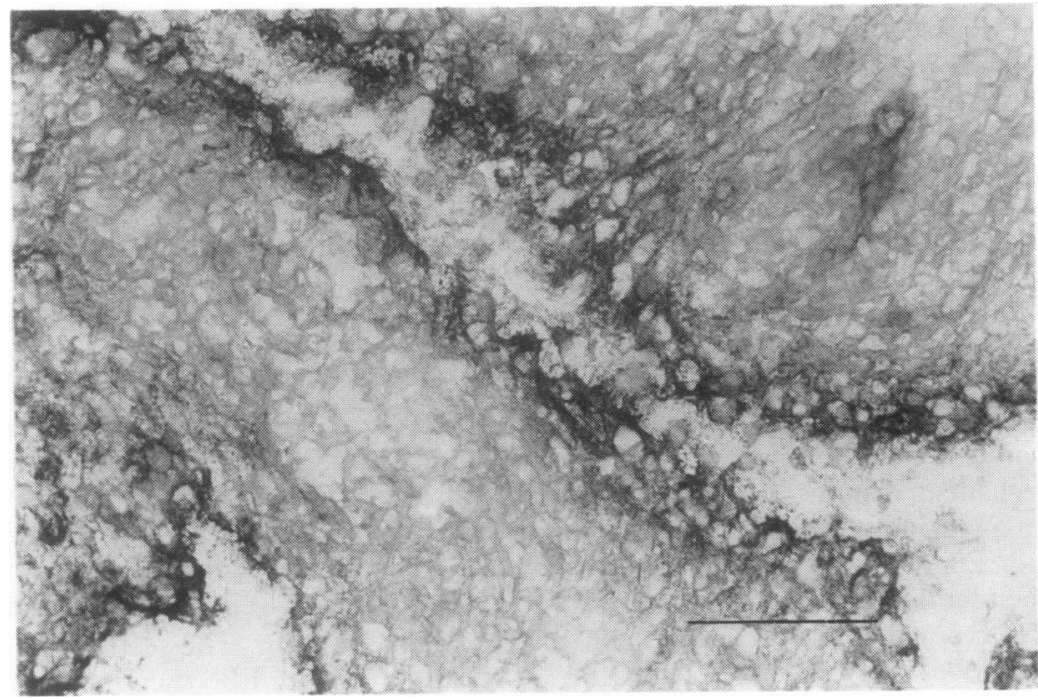

Figure 2 Diffuse immunogold staining with monoclonal antibody $13 C 2$ in section of synovium from a patient with $R A$. Section counterstained with haematoxylin and eosin. Bar $=100 \mu m$.

\section{Results}

Tartrate resistant acid phosphatase activity was found in 38 of 59 synovial specimens studied ( 18 of $30 \mathrm{RA}, 60 \%$; 20 of $29 \mathrm{OA}, 69 \%$ ). The number of tartrate resistant acid phosphatase positive cells varied from one or two per section to more than 100 . These cells were found throughout the synovium but were most often located just below the synovial lining (fig 1). Ten specimens showed more than 20 tartrate resistant acid phosphatase positive cells per section. Seven of these (two RA, five OA) also contained bone or cartilage fragments although not always in close proximity to the tartrate resistant acid phosphatase positive cells. Sixteen of the rheumatoid (53\%) and 11 of the osteoarthritic $(38 \%)$ synovial membranes also contained numerous multinuclear cells in consecutive sections stained with haematoxylin and eosin. In sections that had few $(<10)$ tartrate resistant acid phosphatase cells only $50 \%$ had any multinuclear cells at all. Not all tartrate resistant acid phosphatase positive cells were multinuclear.

All synovial membranes $(n=8$; four $R A$, four $\mathrm{OA})$ that were tested for immunoreactivity to the monoclonal antibody $13 \mathrm{C} 2$ showed similar diffuse staining throughout the synovial lining cells (fig 2). Control tissues (capsule, muscle, and liver) were negative although kidney stained around the tubules as has been previously described. ${ }^{10}$ Of 25 synovial membranes tested for immunoreactivity to the monoclonal antibody $23 \mathrm{C} 6,14$ (six RA, eight OA) were positive but the distribution was different from that of $13 \mathrm{C} 2$, as staining was found on only a few isolated cells scattered throughout the synovium (fig 3). Osteoclastoma sections were strongly positive. Over $80 \%$ of the synovial membranes that contained cells immunoreactive to either $13 \mathrm{C} 2$ or $23 \mathrm{C} 6$ monoclonal antibodies also contained tartrate resistant acid phosphatase positive cells and these were present in greater numbers. In a few sections it was possible to 


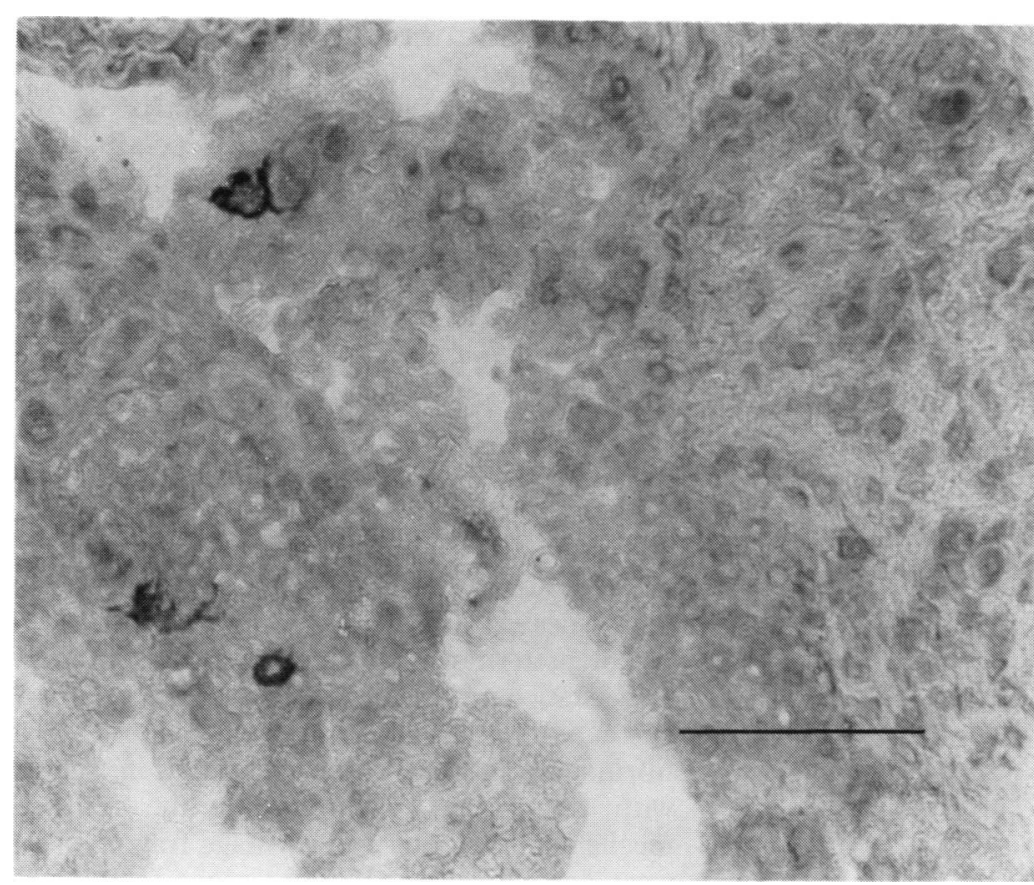

Figure 3 Immunogold staining with monoclonal antibody 23 C6 on individual cells in section of synovium from a patient with $R A$. Section counterstained with haematoxylin and eosin. Bar $=100 \mu \mathrm{m}$. from only two samples (both RA). At day 14, tartrate resistant acid phosphatase positive cells were present in cultures from all 30 specimens examined; however, the numbers present varied from less than 10 to several hundred per well. Morphologically, most appeared as activated macrophage-like cells (fig 5). Fibroblasts, by contrast, showed only very weak tartrate resistant acid phosphatase staining except in areas where the cells were multilayered, in which case staining was often intense. Multinuclear cells were present in 14 cultures (seven RA, seven $\mathrm{OA})$ at two weeks but even within individual wells these multinuclear cells were heterogenous with respect to tartrate resistant acid phosphatase staining (fig 5). Cells immunoreactive to $13 \mathrm{C} 2$ or $23 \mathrm{C} 6$ monoclonal antibodies were present in four out of six rheumatoid and four out of 10 osteoarthritic synovial cell cultures tested. The monoclonal antibodies reacted with both mononuclear and multinuclear cells (fig 6) staining predominantly the cytoplasmic skirt rather than the cell body. This staining was weak compared with the staining of the isolated newborn rabbit bone cells. Cells immunoreactive to the monoclonal antibodies were rare compared with the number of tartrate resistant acid phosphatase positive cells.

Cells from four cultures (two RA, two OA) show colocalisation of tartrate resistant acid phosphatase and 23C6 immunoreactivity (fig 4 $A$ and $B$ ).

There were no significant differences between patients with either RA or OA in frequency or distribution of either tartrate resistant acid phosphatase activity or monoclonal antibody immunoreactivity in synovial membranes. No relation was found with age, sex, duration of disease, or treatment with steroids.

\section{IN VITRO CULTURE}

Cells recovered from mechanically disrupted synovial membranes were plated in vitro. Thirty cultures were established (13 RA, $17 \mathrm{OA}$ ). Fibroblasts became apparent in most cultures during the first week of culture, occurring singly or arising from clumped cells. Tartrate resistant acid phosphatase positive adherent macrophages were seen at seven days in cultures that contained tartrate resistant acid phosphatase positive, multinuclear, and $23 \mathrm{C} 6$ positive cells were separately tested in an in vitro bone resorption assay. None of the four samples tested formed resorption pits even after eight days incubation with the bone slices.

\section{Discussion}

Many complex cell functions including adhesion, migration, proliferation, and differentiation are modulated by the interaction of adhesion molecules with cellular receptors that have transmembrane links to the cytoskeleton.

The integrins are a family of heterodimeric receptors that bind predominantly, but not exclusively, with Arg-Gly-Asp (RGD) sequences of adhesion proteins including fibronectin, laminin, vitronectin, and osteopontin. ${ }^{11}$ The vitronectin receptor, which is highly expressed
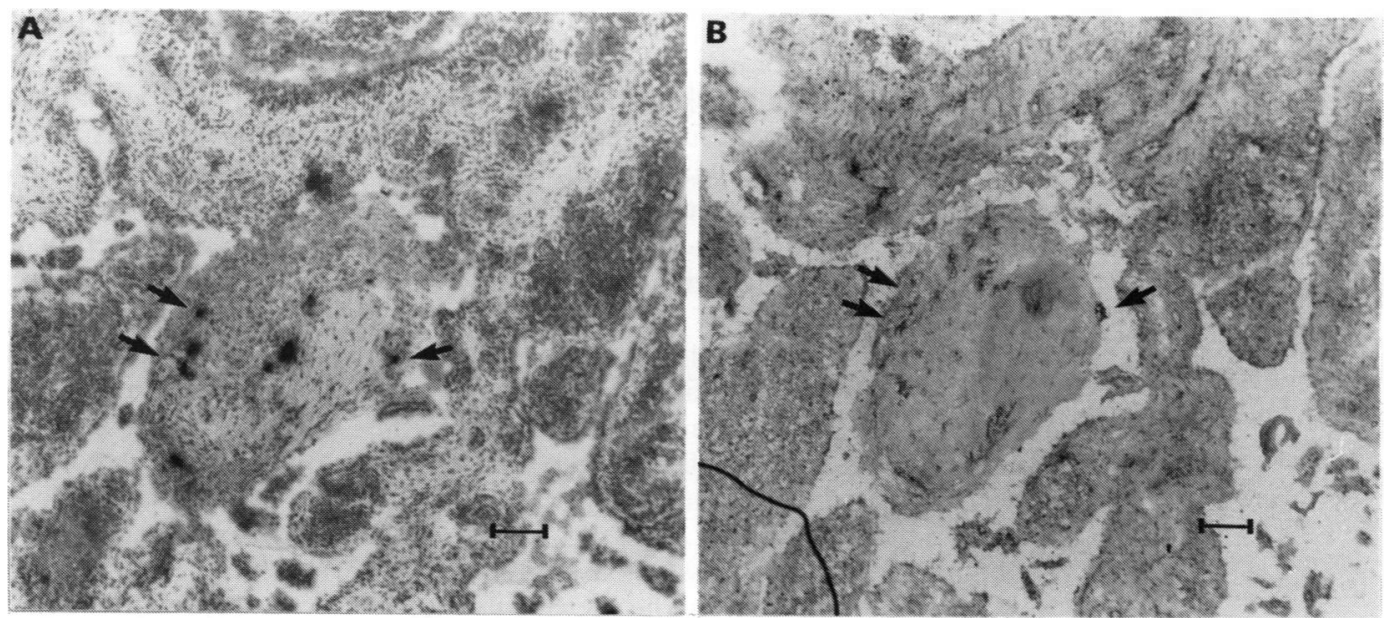

Figure 4 Consecutive sections from rheumatoid synovium stained for $(A)$ tartrate resistant acid phosphatase; $(B) 23 C 6$ antigen. Bar $100 \mu \mathrm{m}$. 


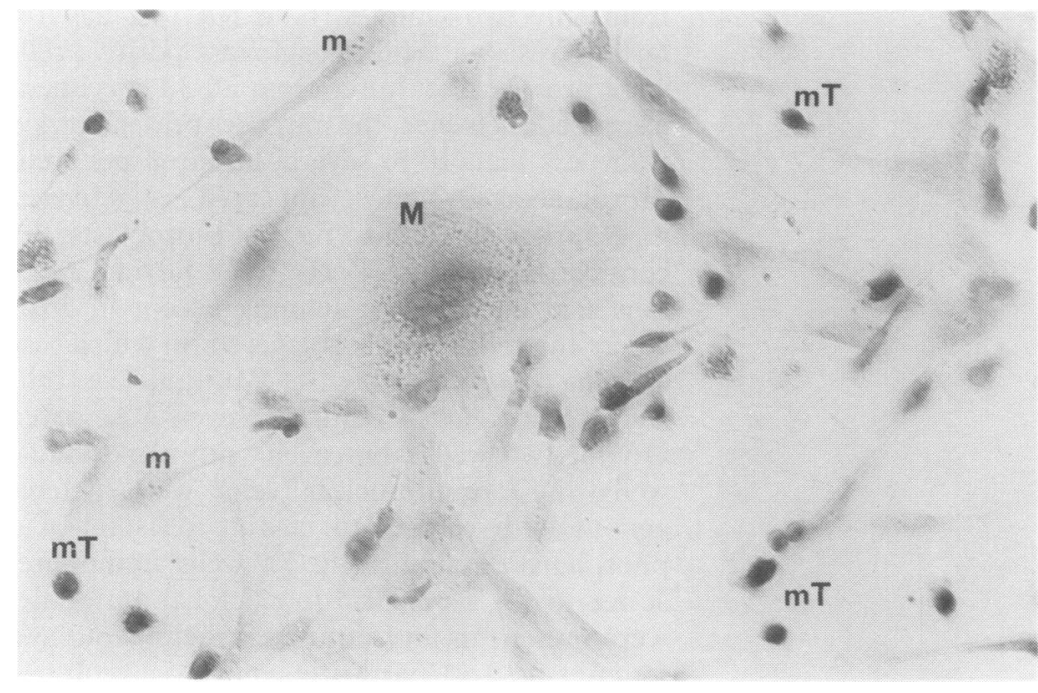

Figure 5 Cells isolated from rheumatoid synovium and cultured for 14 days, stained for tartrate resistant acid phosphatase. Cells counterstained with haematoxylin and eosin. $m T=$ tartrate resistant acid phosphatase positive macrophages, $m=$ tartrate resistant acid phosphatase negative macrophages, $M=$ tartrate resistant acid phosphatase negative multinuclear cell.

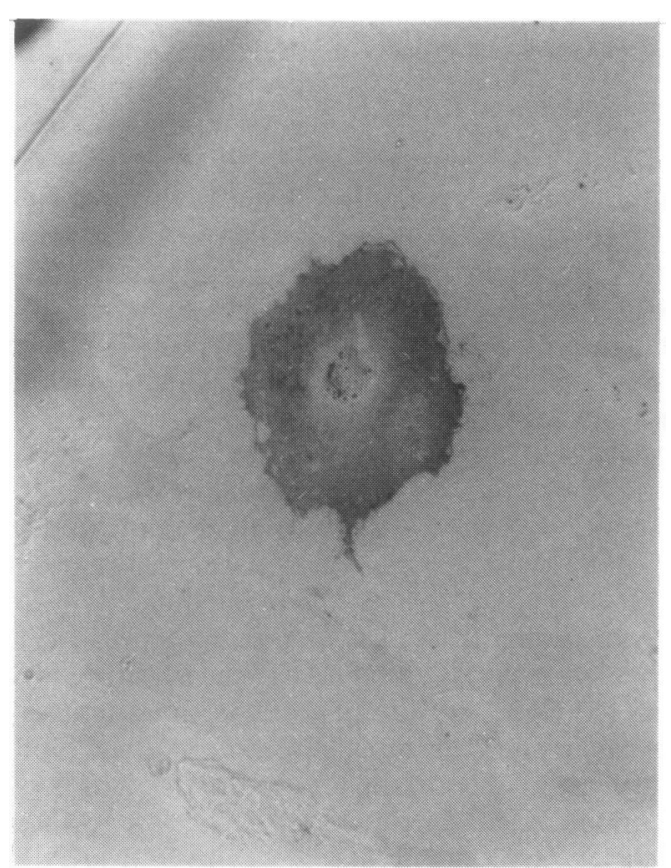

Figure 6 Cells isolated from rheumatoid synovium, cultured for 14 days, and stained with 23C6 monoclonal antibody.

in osteoclast membranes, is comprised of a 140 kilodalton $\alpha \mathrm{v}$ chain in association with a smaller $\beta_{3}$ subunit. Whereas it has been confirmed that $13 \mathrm{C} 2$ interacts solely with the $\alpha \mathrm{v}$ chain, 23C6 has been found to react with an epitope present only on the $\alpha v \beta_{3}$ heterodimer. ${ }^{7}$ It is clear from our study that the epitopes recognised by the monoclonal antibodies $13 \mathrm{C} 2$ and $23 \mathrm{C} 6$ are expressed on different cells within the synovium.

The distribution of staining with monoclonal antibody $13 \mathrm{C} 2$, predominantly in cells in the synovial intima, is similar to that reported by Athanasou $e t$ al. ${ }^{12}$ The nature of the associated $\beta$ chain is unknown but, as the cells in the synovial intima are not stained appreciably by $23 \mathrm{C} 6$, it is unlikely that the $\alpha v \beta_{3}$ vitronectin receptor is present. The $\alpha \mathrm{v}$ chain in association with a $\beta_{5}$ chain forms a functional fibronectin receptor. ${ }^{13}$ Because fibronectin is synthesised by hyperplastic synovial lining cells ${ }^{14}$ and is abundant in the extracellular matrix of the hyperplastic synovial intima, ${ }^{15}$ it is possible that 13C2 labels cells bearing this fibronectin receptor.

Monoclonal antibody $23 \mathrm{C} 6$ was found to stain cells present singly or in aggregates in the subintimal stroma as has previously been described. ${ }^{16}$ The role of these cells and the significance of the high concentration of the vitronectin receptor is unknown. Although recent work ( $M$ Horton, personal communication) has shown that the $\alpha v \beta_{3}$ receptor also interacts with laminin there was no association of the 23C6 stained cells with blood vessels in the tissues examined.

The pattern of integrin expression is unlikely to be static and will be affected by the numbers and activity of inflammatory cells, deposition of fibrinogen, and the presence of debris in contact with the lining cells. Indeed, the removal mechanism for bone and cartilage fragments or wear particles from the joint space is likely to involve interaction of adhesion proteins present in the matrix (for example, osteopontin, bone sialoprotein) or adsorbed from the synovial fluid (for example, fibronectin) with integrins on the cells of the synovial lining. The foreign body giant cells found in association with debris deep within the subintimal stroma, however, were not stained with either $13 \mathrm{C} 2$ or $23 \mathrm{C} 6$, although some did exhibit tartrate resistant acid phosphatase activity.

In vitro, we found that the proportion of dispersed synovial cells that expressed tartrate resistant acid phosphatase activity or were multinuclear increased after the first week of culture under conditions that have been used to produce cells with osteoclast-like characteristics from human marrow ${ }^{17} 18$ or umbilical cord. ${ }^{19}$ Some of the cells satisfied two of the three criteria used in defining osteoclasts-namely, high tartrate resistant acid phosphatase activity, presence of $\alpha \mathrm{v} \beta_{3}$ integrin and multinuclearity. In none of the cultures tested, however, was there evidence of the formation of functional osteoclasts in the pit forming assay. Recent evidence indicates that to resorb bone in this assay osteoclasts (murine, at least) need to be activated. The activation step seems to require cells of the bone marrow stroma to be present in the culture system, and other fibroblasts (for example 3T3) cannot act as substitutes. ${ }^{2021}$ Our data suggest that, in the presence of 1,25dihydroxy vitamin $\mathrm{D}_{3}$ and interleukin $1 \alpha$ cells with some osteoclastic features including the vitronectin receptor are generated in dispersed synovial cell cultures. Because they do not resorb bone, either they are not osteoclasts or human osteoclasts, like their murine counterparts, require activation. The second hypothesis would require that the fibroblastic synovial cells present in synovial cultures are unable to provide the signal to initiate resorption.

In conclusion, we have found synovial cells, both in histological sections and in tissue culture, which show some characteristics of osteoclasts. It seems, however, that fully differentiated osteoclasts are uncommon in synovium 
from patients with either degenerative or inflammatory arthropathies. Synovial osteoclasts could play a physiological part in the clearance of bone debris from the joint but this function, as well as the production of periarticular erosions in $\mathrm{RA}$, may require the participation of adjacent mesenchymal cells.

We thank Dr M Horton, Imperial Cancer Research Fund, St Bartholomew's Hospital, London for generously supplying the monoclonal antisera and Professor J McClure, Department of Pathology, University of Manchester School of Medicine for scanning electron microscopy. This work was supported by the Arthritis and Rheumatism Council for Research.

I Edwards J C W, Willoughby D A. Demonstration of bone marrow derived cells in synovial lining by means of giant marrow derived cells in synovial lining by means of giant intracellular granules

2 Dreher $R$. The origin of synovial type A cells during inflammation: an experimental approach. Immunobiolog 1982; 161: 232-45.

3 Revell P A. Synovial lining cells. Rheumatol Int 1989; 9. 49-51.

4 Bromley M, Woolley D E. Chondroclasts and osteoclasts a subchondral sites of erosion in the rheumatoid joint. Arthritis Rheum 1984; 27: 968-75.

5 Ash P, Loutit J F, Townsend K M. Osteoclasts derive from hematopoietic stem cells according to marker, gian

6 Tinkler S M William D M, Linder J E Johnson N W. Kine $\mathrm{M}$, Wilams $\mathrm{D}$, Linder J. E, Johnson $\mathrm{N}$. Kinetics of osteoclast formation: the significance of blood monocytes as osteoclast precursors during 12-hydroxycholecalciferol-stimulated

7 Davies J, Warwick J, Totty N, Philp R, Helfrich M Horton $M$. The osteoclast functional antigen, implicated i the regulation of bone resorption, is biochemically related to the vitronectin receptor. F Cell Biol 1989; 109: 1817-26.

8 Snipes R G, Lam K-W, Dodd R C, Gray T K, Cohen M S Acid phosphatase activity in mononuclear phagocytes and the U937 cell line. Blood 1986; 67: 729-34.
9 Ropes M W, Blanet G A, Caleb S, Jacox R, Jessar R A. Revision of diagnostic criteria for rheumatoid arthritis. Bull Rheum Dis 1958; 9: 175-6.

10 Horton M A, Lewis D, McNulty K, Pringle J A S, Chambers T J. Monoclonal antibodies to osteoclastomas (giant cell bone tumors): definition of osteoclast specific cellular bone tumors): definition of osteoclast

11 Buck C A, Horwitz A F. Cell surface receptors for extracellular matrix molecules. Annu Rev Cell Biol 1987; 3: 179-205.

12 Athanasou N A, Quinn J, Horton M A, McGee J O'D. New sites of cellular vitronectin receptor immunoreactivity detected with osteoclast-reacting monoclonal antibodies 13C, and 23C6. Bone Miner 1990; 8: 7-22.

13 Smith J W, Vestal D J, Irwin S V, Burke T A, Cheresh D A. Purification and functional characterization of integrin alpha $\mathrm{V}$ beta 5 . An adhesion receptor for vitronectin. $\mathcal{J}$ Biol Chem 1990; 265: 11008-13.

14 Waller H A, Butler M G, McClean J G B, Dowd G S E, Scott $D$ L. Localization of fibronectin in RNA in the rheumatoid synovium by in situ hybridization. Ann Rheum Dis 1992; 51: $735-40$.

15 Scott D L, Delamere J P, Walton K W. The distribution of fibronectin in the pannus in rheumatoid arthritis. Brf Exp Pathol 1981; 62: 362-8.

16 Salisbury A K, Duke O, Poulter L W. Macrophage like cells of the pannus area in rheumatoid arthritic joints. Scand $\mathcal{F}$ Rheumatol 1987; 16: 263-72.

17 MacDonald B R, Takahashi N, McManus L M, Holahan J, Mundy G R, Roodman G D. Formation of multinucleated cells that respond to osteotropic hormones in long term human bone marrow cultures. Endocrinology 1987; 120: 2326-33.

18 Pfeilschifter J, Chenu C, Bird A, Mundy G R, Roodman G D. Interleukin- 1 and tumor necrosis factor stimulate the formation of human osteoclast like cells in vitro. $f$ Bone Miner Res 1989; 4: 113-8.

19 Orcel P, Bielakoff J, Vernejoue M C. Formation of multinucleated cells with osteoclast precursor features in human cord monocyte cultures. Anat Rec 1990; 226: 1-9.

20 Hattersley G, Chambers T J. Generation of osteoclasts from hemopoietic cells and a multipotential cell line in vitro. f Cell Physiol 1989; 140: 478-82.

21 Udagawa $\mathrm{N}$, Takahashi $\mathrm{N}$, Akatsu $\mathrm{T}$, et al. The bone marrow-derived stromal cell lines MC 3T3-G2/PA6 and ST2 support osteoclast-like cell differentiation in cocultures with mouse spleen cells. Endocrinology 1989; 125: 1805-13. 